University of South Carolina

Scholar Commons

4-2013

\title{
Enhanced Nucleate Boiling on Horizontal Hydrophobic- Hydrophilic Carbon Nanotube Coatings
}

\author{
Xianming Dai \\ University of South Carolina, daix@email.sc.edu \\ Xinyu Huang \\ University of South Carolina - Columbia, xyhuang@sc.edu \\ Fanghao Yang \\ University of South Carolina, yang74@email.sc.edu \\ Xiaodong Li \\ University of South Carolina - Columbia, lixiao@cec.sc.edu \\ Joshua Sightler
}

See next page for additional authors

Follow this and additional works at: https://scholarcommons.sc.edu/emec_facpub

Part of the Applied Mechanics Commons, and the Biological and Chemical Physics Commons

\section{Publication Info}

Published in Applied Physics Letters, Volume 102, Issue 16, 2013, pages 161605-1-161605-5.

(C) Applied Physics Letters, 2013, American Institute of Physics

Dai, X., Huang, X., Yang, F., Li, X., Sightler, J., Yang, Y., Li, C. (2013). Enhanced Nucleate Boiling on

Horizontal Hydrophobic-Hydrophilic Carbon Nanotube Coatings. Applied Physics Letters, 102(16),

161605-1-161605-5.

http://dx.doi.org/10.1063/1.4802804

This Article is brought to you by the Mechanical Engineering, Department of at Scholar Commons. It has been accepted for inclusion in Faculty Publications by an authorized administrator of Scholar Commons. For more information, please contact digres@mailbox.sc.edu. 


\section{Author(s)}

Xianming Dai, Xinyu Huang, Fanghao Yang, Xiaodong Li, Joshua Sightler, Yingchao Yang, and Chen Li 


\section{Enhanced nucleate boiling on horizontal hydrophobic-hydrophilic carbon nanotube coatings}

Xianming Dai, Xinyu Huang, Fanghao Yang, Xiaodong Li, Joshua Sightler, Yingchao Yang, and Chen Li

Citation: Appl. Phys. Lett. 102, 161605 (2013); doi: 10.1063/1.4802804

View online: http://dx.doi.org/10.1063/1.4802804

View Table of Contents: http://aip.scitation.org/toc/apl/102/16

Published by the American Institute of Physics

\section{Articles you may be interested in}

Structured surfaces for enhanced pool boiling heat transfer

Appl. Phys. Lett. 100, 241603241603 (2012); 10.1063/1.4724190

Effect of liquid spreading due to nano/microstructures on the critical heat flux during pool boiling Appl. Phys. Lett. 98, 071908071908 (2011); 10.1063/1.3555430

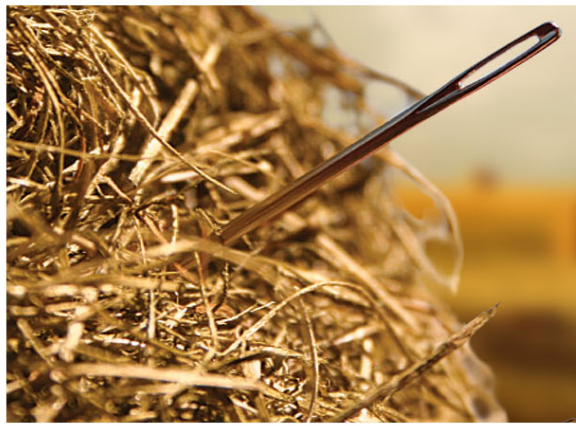

FIND THE NEEDLE IN THE HIRING HAYSTACK

POST JOBS AND REACH THOUSANDS OF QUALIFIED SCIENTISTS EACH MONTH.

PHYSICS TODAY IJOBS WWW.PHYSICSTODAY.ORG/JOBS 


\title{
Enhanced nucleate boiling on horizontal hydrophobic-hydrophilic carbon nanotube coatings
}

\author{
Xianming Dai, Xinyu Huang, Fanghao Yang, Xiaodong Li, Joshua Sightler, Yingchao Yang, \\ and Chen $\mathrm{Li}^{\mathrm{a}}$ ) \\ Department of Mechanical Engineering, University of South Carolina, Columbia, South Carolina 29208, USA
}

(Received 14 February 2013; accepted 9 April 2013; published online 26 April 2013)

\begin{abstract}
Ideal hydrophobic-hydrophilic composite cavities are highly desired to enhance nucleate boiling. However, it is challenging and costly to fabricate these types of cavities by conventional micro/nano fabrication techniques. In this study, a type of hydrophobic-hydrophilic composite interfaces were synthesized from functionalized multiwall carbon nanotubes by introducing hydrophilic functional groups on the pristine multiwall carbon nanotubes. This type of carbon nanotube enabled hydrophobic-hydrophilic composite interfaces were systematically characterized. Ideal cavities created by the interfaces were experimentally demonstrated to be the primary reason to substantially enhance nucleate boiling. (C) 2013 AIP Publishing LLC. [http://dx.doi.org/10.1063/1.4802804]
\end{abstract}

Nucleate boiling is widely used in a variety of heat transfer and chemical reaction applications. The popular techniques in enhancing nucleate boiling include applying micro/nanoscale structures ${ }^{1}$ and hydrophilic coatings. ${ }^{2}$ Guided by nucleate boiling theory ${ }^{3}$ and the most recent study ${ }^{4}$ ideal boiling surfaces should be hydrophilic to delay filmwise transition and contain hydrophobic cavities to trap gases or vapor by taking advantages of both of the hydrophilic and hydrophobic properties. ${ }^{4}$

In this experimental study, hydrophobic-hydrophilic composite interfaces were synthesized from functionalized multiwall carbon nanotubes (FMWCNTs) by introducing hydrophilic functional groups on the pristine multiwall carbon nanotube (MWCNT) surfaces. The ideal boiling surfaces created by the carbon nanotube (CNT) enabled hydrophobic-hydrophilic composite interfaces were experimentally demonstrated to effectively enhance nucleate boiling in the horizontal direction.

Enhanced transport phenomena were reported on partially hydrophobic and partially hydrophilic interfaces. ${ }^{5,6}$ For examples, Daniel et al. ${ }^{7}$ reported that the interfaces with hydrophobic-hydrophilic composite wettabilities were able to accelerate drop motion, ${ }^{8}$ and thus significantly enhance the condensation heat transfer. Miljkovic et al. ${ }^{9}$ observed that partially wetting droplets exhibited a much higher growth rate than suspended droplets during dropwise condensation. Martines et al. ${ }^{6}$ confirmed that a forest of hydrophilic/ hydrophobic slender pillars was shown to be the most effective superwettable/water-repellent configuration. CottinBizonne et al. ${ }^{10}$ found that partial dewetting on a composite interface was superior in producing a "water repellent" effect and thus in reducing the surface friction. In addition, a superhydrophobic and sticky interface was found to be exceptional in transporting small volumes of liquids without loss. ${ }^{11,12}$ Enhanced nucleate boiling was experimentally demonstrated on micro-fabricated hydrophobic-hydrophilic surfaces. ${ }^{13}$ However, the enhanced nucleate boiling on CNT-enabled hydrophobic-hydrophilic interfaces was not

\footnotetext{
${ }^{\text {a) }}$ Author to whom correspondence should be addressed. Electronic mail: Li01@mailbox.sc.edu.
}

reported. More importantly, the conventional micro/nanofabricated hydrophobic-hydrophilic composite interfaces ${ }^{6,13}$ are usually costly and challenging to tune the wettability in a controlled manner.

CNTs with defects, which were generally regarded to have mechanical, ${ }^{14}$ electrical, ${ }^{15}$ and thermal disadvantages, ${ }^{16}$ were shown to exhibit intriguing properties for many emerging applications such as nano-sensors, ${ }^{17}$ super conductors, ${ }^{18}$ catalysts, ${ }^{19}$ and field effect transistors. ${ }^{20}$ In this study, the hydrophobic-hydrophilic composite interfaces were synthesized by partially oxidizing pristine MWCNT surfaces to form hydrophilic carboxylic and hydroxylic functional groups on the defect sites of MWCNTs. ${ }^{19}$ The commercially available MWCNTs were initially oxidized in aqua regia solutions (Figs. 1(a) and 1(b)). Then, $5 \mathrm{mg}$ of synthesized FMWCNTs with $20 \mathrm{mg}$ of $5 \%$ Nafion solution were ultrasonically dispersed in the isopropyl alcohol to form "inks." Greater dispersions of FMWCNTs were obtained by ultrasonically mixing with isopropyl alcohol, and adding amphiphilic Nafion. ${ }^{21}$ The well-dispersed FMWCNT "inks" were deposited on a copper substrate by an ultrasonic spray coater. Nafion served as a gluing media to strengthen the bonding forces, which were characterized by the microscratch tests (supplementary material). ${ }^{22}$ Oxygen plasma was used to further functionalize the FMWCNT coated samples, which added more hydrophilic functional groups ${ }^{23}$ (Fig. 1(c)). The extent of functionalization can be conveniently tuned by varying the reaction time and the oxygen flow rate. Here, Nafion was also used to strengthen the bonding of the FMWCNT coatings with the substrate, introduce the additional hydrophobic functional groups $\left(-\mathrm{CF}_{2}-\right)$ and hydrophilic sulfuric acid groups $\left(-\mathrm{SO}_{3} \mathrm{H}\right)$ and improve the dispersion.

In this study, the distribution and concentration of hydrophilic groups were approximately indicated by tracer particles (Figs. 1(d) and 1(e)) due to the challenge in directly visualizing the hydrophobic-hydrophilic network on FMWCNTs. Positively charged platinum ions $\left(\mathrm{Pt}^{4+}\right)$ from chloroplatinic acid $\left(\mathrm{H}_{2} \mathrm{PtCl}_{6}\right)$ were used to locate the functional groups on the FMWCNT wires and bundles since the reduced platinum particles tend to nucleate on the defects of 


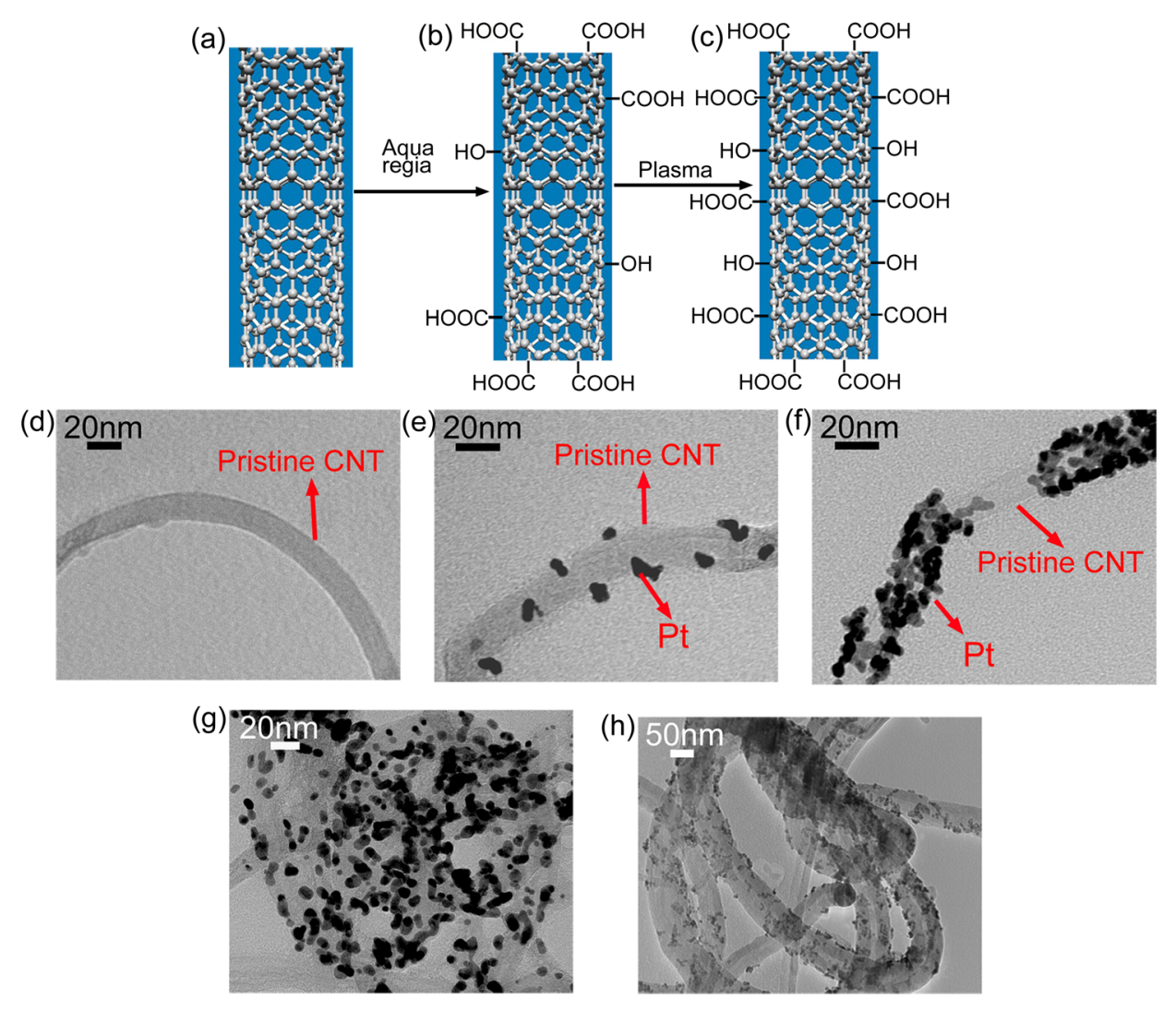

FIG. 1. Synthesis and characterization of the hydrophobic-hydrophilic FMWCNTs. (a) Pristine MWCNTs. (b) Aqua regia oxidized MWCNTs. (c) Plasma treated FMWCNTs. (d) A pristine MWCNT without defects. (e) Defects on a slightly functionalized FMWCNT indicated by Pt particles. (f) Defects on a deeply functionalized FMWCNT indicated by Pt particles. (g) Hydrophobic and hydrophilic areas on FMWCNT coated interfaces. (h) Interconnected cavities formed by partially hydrophobic and partially hydrophilic FMWCNTs.

FMWCNTs. ${ }^{19}$ The functional groups grow preferentially in the defect sites. ${ }^{24}$ As a result, Pt loaded areas were taken favorably as functionalized regions.

The hydrophilic functional groups grown on the defected areas are at the nanoscale. Thus, it is challenging to quantify the ratio of the hydrophilic surface areas in the porous coatings. In this study, the macroscopic static contact angle measurements were employed to characterize the wettability of the hydrophobic-hydrophilic composite interfaces. The pristine MWCNT coatings are hydrophobic ${ }^{25}$ and nonadhesive (Fig. 2(a)). The straw-like pristine MWCNT coated interface is superhydrophobic ${ }^{26}$ and non-wettable even totally immersed in water. In contrast, the dry FMWCNT coatings on a flat copper substrate were apparently hydrophobic, but adhesive, which was evidenced by a water droplet adhering to the coatings with a tilt angle of $180^{\circ}$ (Figs. 2(b) and 2(c)). Although having almost the same surface morphologies as the non-adhesive pristine MWCNT coatings, the FMWCNT coatings showed stickiness, which is believed to be induced by the hydrophilic functional groups on the defect areas (Fig. 1(e)). This indicated that the Van der Waals ${ }^{11}$ and/or the capillary force between the nanostructured interfaces and water are introduced by the partial wetting. ${ }^{6}$ Therefore, transitions between the CassieBaxter and Wenzel $^{27}$ states can be induced by enhancing stickiness. ${ }^{28}$ When the wetting behavior changes from the Cassie mode to the Wenzel mode, the liquid droplet can at least partially fill the cavities of the rough substrates with a reduced apparent contact angle. ${ }^{29}$ The characterization of sticky property clearly indicated the effect of partial hydrophilicity on surface wettabilities (Figs. 1(d) and 1(e)). FMWCNT interfaces were shown to be wettable (Fig. 2(d)). The reason could be the capillary flow induced at the solidliquid-gas interfaces. As a result, the majority of pores can be filled with water, causing the interfaces to lose its waterrepellent properties ${ }^{28}$ as shown in Fig. 2(d). These observations are consistent with the hydrophobic-hydrophilic wettability of FMWCNTs as shown in the TEM images

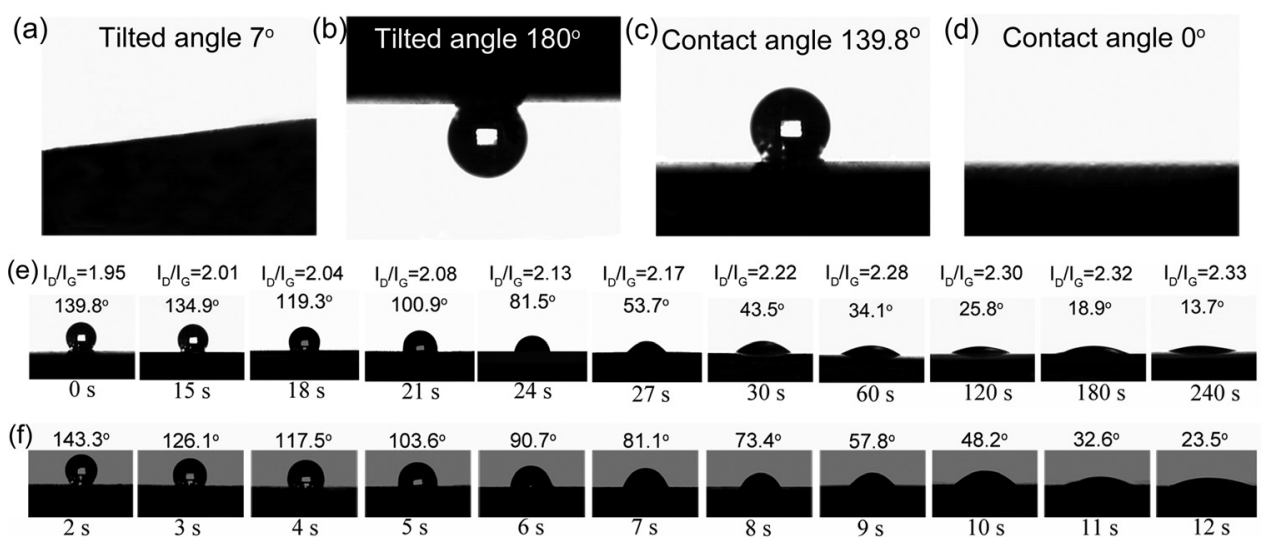

FIG. 2. Characterization of the wettability of hydrophobic-hydrophilic FMWCNTs interfaces. (a) On pristine CNT coated interface with a tilt angle of $7^{\circ}$. (b) On FMWCNT coated interface with a tilt angle of $180^{\circ}$. (c) On dry FMWCNT coated interface. (d) On wet FMWCNT coated interface. (e) Contact angle as a function of Raman $\mathrm{I}_{\mathrm{D}} / \mathrm{I}_{\mathrm{G}}$ ratio and plasma treatment time (on FMWCNT coated flat copper surface). (f) Contact angle as a function of plasma treatment time on pristine MWCNT coated flat copper surface. 
(Figs. 1(g) and 1(h)). In contrast to the non-wettable MWCNT coating, this wettable FMWCNT coated interface can improve the local liquid supply during the nucleate boiling process as the whole interfaces are immersed in the liquids.

Regular FMWCNT wires or bundles, i.e., those only treated by aqua regia, contain fewer hydrophilic functional groups (Fig. 1(e)) than oxygen plasma treated FMWCNTs (Fig. 1(f)). This observation implies the superior tunability of hydrophobic-hydrophilic composite wettability enabled by the enhanced FMWCNTs. In this study, the relative hydrophilicity of individual FMWCNT wires and coatings can be conveniently tuned by controlling the plasma treatment time. Fig. 2(e) quantitatively shows that the apparent contact angle of FMWCNT interfaces decreased with increasing plasma treatment time at a given oxygen flow rate. Raman analysis showed that more defects were introduced by longer plasma treatment time, ${ }^{30}$ e.g., with more $\mathrm{C}=\mathrm{O}, \mathrm{O}-\mathrm{C}=\mathrm{O}$ and $\mathrm{O}-\mathrm{H}$ groups ${ }^{23}$ which were indicated by an increasing $\mathrm{I}_{\mathrm{D}} / \mathrm{I}_{\mathrm{G}}$ ratio $^{30}$ (refer to the supplement information). To better understand the effects of plasma treatment on the wetting property of CNTs, the change of static contact angle on pristine MWCNTs coatings without Nafion was studied. Longer plasma treatment time resulted in a higher hydrophilicity, which was indicated by the reduced contact angle (Fig. 2(f)). The required time of plasma treatment was much less than that of FMWCNTs coatings with Nafion. This could be a result of protection effects from Nafion wrapping.

Ideal boiling surfaces to achieve high heat transfer coefficient (HTC) and critical heat flux (CHF) should have a combination of features: high active nucleation site density, optimized cavities that are favorable for bubble growth and departure and in reducing superheat, minimized flow resistance to improve liquid supply, and an evenly distributed liquid film to induce and promote thin film evaporation. The straw-like FMWCNT coatings, which can randomly form a large number of interconnected pores or cavities (Fig. 1(h)) with partially hydrophobic and partially hydrophilic areas (Fig. 1(g)), could create ideal nucleate boiling surfaces.

In general, there are four typical types of boiling surfaces as schematically shown in Fig. 3(a). The type I boiling surfaces with superhydrophilic cavities can substantially reduce superheat, delay the transition boiling, and hence enhance HTC as guided by the nucleate boiling theory, ${ }^{3}$ but they greatly suffer from flooding. Additionally, the type II boiling surfaces with superhydrophobic cavities can accelerate bubble departure processes, but result in extremely high superheat. According to the most recent study, ${ }^{4}$ the type III boiling surfaces with superhydrophobic-superhydrophilic surfaces are ideal for nucleate boiling by taking advantages of both hydrophilic and hydrophobic properties. However, it is challenging to fabricate type III boiling surfaces by traditional micro/nano fabrication techniques. ${ }^{13}$ In this study, the type IV boiling surfaces (right in Fig. 3(a)), which were created by the FMWCNTs, intrinsically include a large amount of submicro/nanoscale interconnected cavities with unique hydrophobic-hydrophilic composite wettability.

An experimental pool boiling study was performed to evaluate type IV boiling surfaces. ${ }^{22}$ In order to take full advantages of the supernucleating interfaces, the mixture of Nafion and FMWCNTs (NFMWCNTs) was coated on twolayer copper mesh screens to form hierarchical structures. The hierarchical structures contained microscale pores (Fig. 3(b)) and nanopores (Fig. 3(c)) created by copper meshes and NFMWCNT coatings. Microscale pores were designed to reduce the liquid flow resistance. In total, five samples were experimentally studied (refer to the supplementary information). Flat copper surfaces were used to calibrate the test apparatus, and two-layer sintered copper woven mesh screens were used as the baseline. Three two-layer mesh screens coated with approximately $800 \mathrm{~nm}$ thick NFMWCNTs were tested to determine the effects of the hydrophobic-hydrophilic composite interfaces on nucleate boiling.

From the five boiling curves presented in Fig. 3(d), the overall nucleate boiling HTC on NFMWCNT coatings with and without oxygen plasma treatments was significantly enhanced, compared to the bare two-layer copper mesh screens. However, such an enhancement was found to decrease with an increasing amount of hydrophilic groups. Specifically, for a given heat flux $135 \mathrm{~W} / \mathrm{cm}^{2},{ }^{2}$ the HTC on the regular NFMWCNT coated sample was dramatically (a) Type I
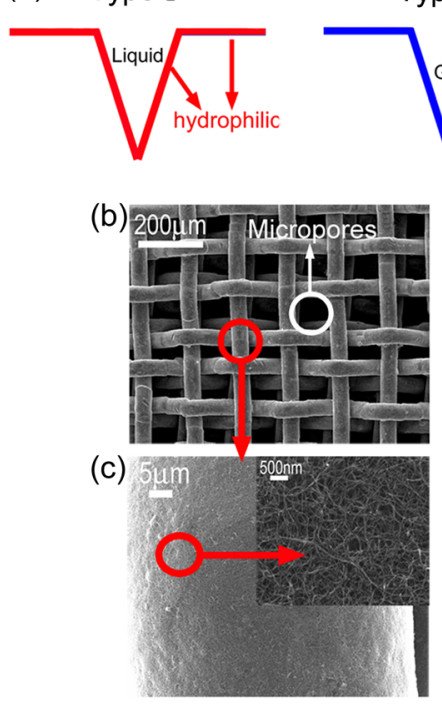

Type II

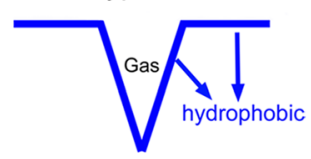

(d)

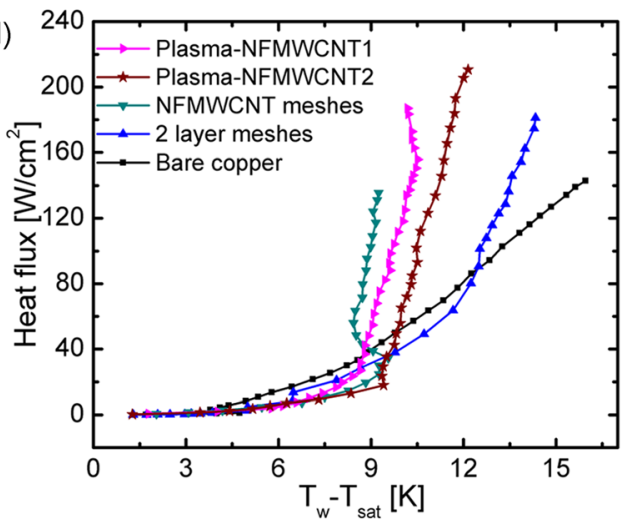

Type IV

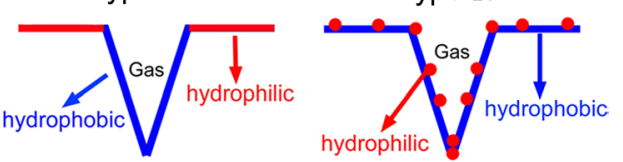
nucleate boiling on the supernucleating interfaces created by FMWCNTs. (a) Four types of cavities for nucleate boiling. (b) Two-layer copper meshes sintered on smooth copper. (c) FMWCNTs coated on mesh wires. (d) Pool boiling curves, where FMWCNT meshes denote "regular FMWCNT coated two-layer meshes;" Plasma-FMWCNT1-“intermediately functionalized FMWCNT coated two-layer meshes (8 min plasma treatment);" and Plasma-FMWCNT2 - "deeply functionalized FMWCNTs coated two-layer meshes (15 min plasma treatment)." 
enhanced by $46.5 \%$, but the enhancement was reduced to approximately $32.7 \%$ and $20.8 \%$ on two plasma treated samples, i.e., plasma-NFMWCNT 1 and 2, respectively. Additionally, CHF was significantly reduced from 181.1 to $135.5 \mathrm{~W} / \mathrm{cm}^{2}$ on the regular NFMWCNT coated sample, because the amount of functional groups on the regular NFMWCNTs was limited and degraded the local wettability and hence, the liquid supply, as indicated in Fig. 1(e). This observation is consistent with two oxygen plasma-treated NFMWCNTs coatings, where CHFs were found to increase from $181.1 \mathrm{~W} / \mathrm{cm}^{2}$ to $187.2 \mathrm{~W} / \mathrm{cm}^{2}$ and $210.5 \mathrm{~W} / \mathrm{cm}^{2},{ }^{2}$ respectively. It was experimentally validated that more hydrophilic functional groups lead to the improvement of local liquid supply and, therefore, the delay of transition boiling. The onset of nucleate boiling (Fig. 3(d)) on regular NFMWCNTs or plasma-treated NFMWCNTs was significantly delayed compared with the bare meshes. That could be caused by the reduced cavity opening size formed by NFMWCNTs, as indicated by nucleate boiling theory. ${ }^{3}$

To mechanistically understand the enhanced nucleate boiling on NFMWCNT coatings, a visualization study was performed to understand the bubble dynamics on three flat substrates: bare copper, NFMWCNT coated copper, and oxygen plasma treated NFMWCNT coated copper at a given super heat, $\Delta \mathrm{T}=9 \pm 0.5^{\circ} \mathrm{C}^{22}$ The dramatic enhancement on the NFMWCNTs was caused by the significant increase of active nucleation site density, bubble growth rate, and bubble departure frequency on the hydrophobic-hydrophilic composite cavities (Fig. 4). The active nucleation site density on NFMWCNT coatings with and without oxygen plasma treatments was at least one order of magnitude higher than that on the bare copper substrate. The primary reasons could be in two-folds during the entire nucleate boiling process. First, the total surface area was significantly augmented because of the NFWMCNT coatings. Second, the active nucleation site density was dramatically enhanced because of the prevention of cavities (formed by NFMWCNTs) from flooding due to their partially hydrophobic property. The highest nucleation site density was on the regular NFMWCNT coatings (Fig. 4(a)). Bubble growth rate on the NFMWCNT coatings with and without oxygen plasma treatments (Fig. 4(b)) was also significantly higher than that on the bare copper surface, which indicated that the evaporation in the microlayer was primarily enhanced by the hydrophilic groups. However, having a fewer number of hydrophilic groups resulted in a relatively higher evaporating rate on the microlayer according to the visualization study. This could be caused by the decreased local drag resulting from fewer hydrophilic groups, which would enhance the water supply to the nanopores or cavities underneath (refer to the supplementary videos). ${ }^{22}$ Additionally, bubble departure frequency from NFMWCNT coatings was higher (Fig. 4(c)) and the average bubble departure diameter was smaller (Fig. 4(d)) compared with those on the bare copper interface. The reason can be a combined effect of the reduced anchoring capillary force on hydrophobic-hydrophilic interfaces and the increased inertia force resulting from the bubble growth due to the enhanced evaporation in the microlayer (refer to the supplementary videos). ${ }^{22}$

The slightly functionalized NFMWCNT interfaces performed even better in terms of bubble generation, growth, and departure than the oxygen plasma treated NFMWCNT interfaces. This observation confirms that hydrophobic cavities are superior in promoting the bubble departure processes, and hence, in enhancing the HTC, while hydrophilic surfaces are more suitable for improving the local wettability and therefore delaying the transition boiling, i.e., enhancing CHF. This study experimentally demonstrates that the enhancements of HTC and CHF can be achieved by inducing hydrophobic-hydrophilic composite wettability, which can be tuned by varying the concentration of hydrophilic functional groups.

To further distinguish the effects of hydrophilicity and defect density on boiling heat transfer enhancement, FMWCNT coatings with and without fluoridations were studied. FMWCNT was treated by fluorine gas to achieve hydrophobic fluorinated FMWCNT (F-FMWCNT), where more defect areas were introduced and a large amount of hydrophobic $\mathrm{C}_{2} \mathrm{~F}$ functional groups were created. ${ }^{31,32}$ The completely hydrophobic F-FMWCNT and partially hydrophilic FMWCNT were coated on the flat copper substrates without any additives. The contact angles were measured at $146.2^{\circ}$ and $19.3^{\circ}$, respectively (Fig. 4(e)). Boiling heat transfer rate on the F-FMWCNT coatings was lower than that on the FMWCNT coatings. Additionally, the Raman spectroscopy examined that the F-FMWCNT had a higher defect density than the FMWCNT (indicated by the higher $\mathrm{I}_{\mathrm{D}} / \mathrm{I}_{\mathrm{G}}$ ratio as shown in Fig. 4(e)). Therefore, the enhancement of
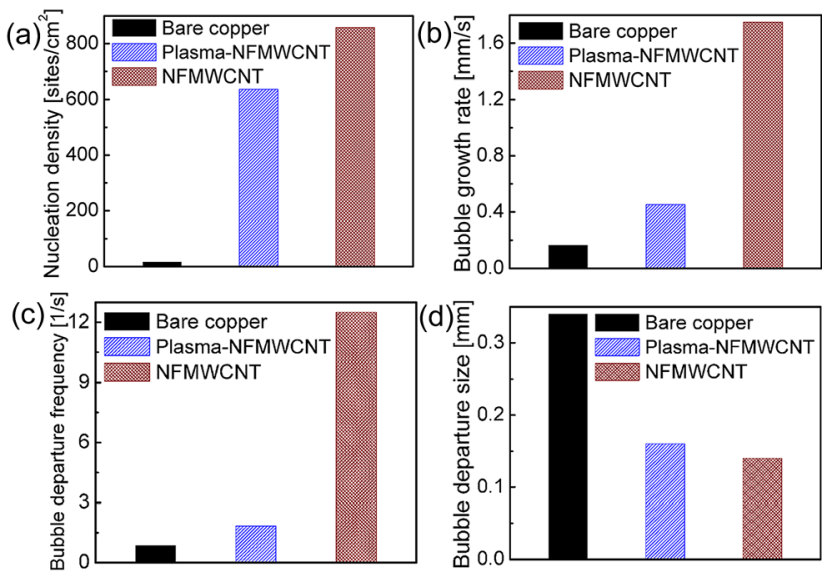

(e)

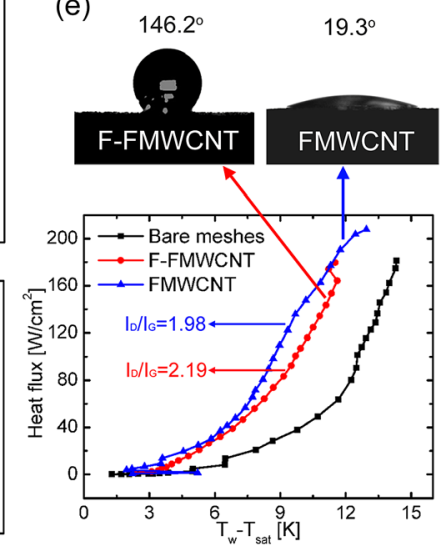

FIG. 4. Bubble dynamics. (a) Comparison of the nucleation site density. (b) Comparison of the bubble growth rate. (c) Comparison of the bubble departure frequency. (d) Comparison of the average bubble departure size. (e) The effects of hydrophilicity and defect density on boiling heat transfer. 
boiling heat transfer should be primarily caused by the introduced hydrophilicity instead of the defect density in the CNT enabled hydrophobic-hydrophilic interfaces.

In summary, interfaces with hydrophobic-hydrophilic composite wettabilities were synthesized from the functionalized MWCNTs by partially oxidizing pristine MWCNT surfaces to form hydrophilic carboxylic and hydroxylic functional groups on the defect sites. Amphiphilic Nafion was added to strengthen the bonding of the FMWCNT coatings and to introduce additional hydrophobic functional groups $\left(-\mathrm{CF}_{2}-\right)$ and hydrophilic sulfuric acid groups $\left(-\mathrm{SO}_{3} \mathrm{H}\right)$. The distribution and concentration of hydrophilic groups were approximately indicated by platinum nano-particles. The apparent contact angle of the interface was shown to be conveniently tuned in a large range by varying the concentration of the intrinsically hydrophilic functional groups. The present nano-engineered interface, which is composed of numerous submicro/nanoscale interconnected cavities with partially hydrophobic and partially hydrophilic wettability, was experimentally demonstrated to be superior in enhancing nucleate boiling. This is because the hydrophobic-hydrophilic interfaces effectively enhance nucleation density, bubble growth rate, and bubble departure frequency, and thus considerably improve nucleate boiling. Hydrophobic F-FMWCNTs with higher defect densities were shown to perform worse than the hydrophilic FMWCNTs in boiling heat transfer. This indicated that the nucleate boiling should be primarily enhanced by the introduced hydrophilicity, instead of the defect density in the CNT enabled hydrophobic-hydrophilic interfaces. Moreover, this nano-engineered interface can be potentially used to enhance transport phenomena at micro/nano scale, such as transporting liquid without loss, ${ }^{11}$ reducing friction, ${ }^{10}$ and manipulating droplet movement. ${ }^{7}$

This work was supported by the startup funds of USC (University of South Carolina) to Dr. C. Li and Dr. X. Huang and the Office of Naval Research (Program Officer Dr. Mark Spector) under Grant No. N000141210724 to Dr. C. Li. The authors thank the USC Electron Microscopy Center for instrument use, scientific and technical assistance. Professor Robert H. Hauge's help in synthesizing the fluorinated FMWCNTs is greatly appreciated. The authors also gratefully thank Dr. Jeff Morehouse in USC for his professional proof-reading and Dr. Xingjie Zan in USC for his assistance in contact angle measurements.
${ }^{1}$ C. Li, Z. Wang, P.-I. Wang, Y. Peles, N. Koratkar, and G. P. Peterson, Small 4(8), 1084 (2008).

${ }^{2}$ B. Feng, K. Weaver, and G. P. Peterson, Appl. Phys. Lett. 100(5), 053120 (2012).

${ }^{3}$ Y. Y. Hsu, Trans. ASME J. Heat Transfer 84, 207 (1962).

${ }^{4}$ N. A. Patankar, Soft Matter 6(8), 1613 (2010).

${ }^{5}$ D. Chandler, Nature 437(7059), 640 (2005).

${ }^{6}$ E. Martines, K. Seunarine, H. Morgan, N. Gadegaard, C. D. W. Wilkinson, and M. O. Riehle, Nano Lett. 5(10), 2097 (2005).

${ }^{7}$ S. Daniel, M. K. Chaudhury, and J. C. Chen, Science 291(5504), 633 (2001).

${ }^{8}$ D. T. Wasan, A. D. Nikolov, and H. Brenner, Science 291(5504), 605 (2001).

${ }^{9}$ N. Miljkovic, R. Enright, and E. N. Wang, ACS Nano 6(2), 1776 (2012).

${ }^{10}$ C. Cottin-Bizonne, J.-L. Barrat, L. Bocquet, and E. Charlaix, Nature Mater. 2(4), 237 (2003).

${ }^{11}$ M. H. Jin, X. J. Feng, L. Feng, T. L. Sun, J. Zhai, T. J. Li, and L. Jiang, Adv. Mater. 17(16), 1977 (2005).

${ }^{12}$ Z.-G. Guo and W.-M. Liu, Appl. Phys. Lett. 90(22), 223111 (2007).

${ }^{13}$ A. R. Betz, J. Xu, H. Qiu, and D. Attinger, Appl. Phys. Lett. 97(14), 141909 (2010).

${ }^{14}$ S. L. Mielke, D. Troya, S. Zhang, J. L. Li, S. P. Xiao, R. Car, R. S. Ruoff, G. C. Schatz, and T. Belytschko, Chem. Phys. Lett. 390(4-6), 413 (2004).

${ }^{15}$ Y. Fan, B. R. Goldsmith, and P. G. Collins, Nature Mater 4(12), 906 (2005).

${ }^{16}$ S. Berber, Y. K. Kwon, and D. Tomanek, Phys. Rev. Lett. 84(20), 4613 (2000).

${ }^{17}$ P. Qi, O. Vermesh, M. Grecu, A. Javey, Q. Wang, H. Dai, S. Peng, and K. J. Cho, Nano Lett. 3(3), 347 (2003).

${ }^{18}$ S. Agrawal, M. S. Raghuveer, H. Li, and G. Ramanath, Appl. Phys. Lett. 90(19), 193104 (2007).

${ }^{19}$ J.-P. Tessonnier, A. Villa, O. Majoulet, D. S. Su, and R. Schlögl, Angew. Chem., Int. Ed. 48(35), 6543 (2009).

${ }^{20}$ Y. Lu, S. Bangsaruntip, X. Wang, L. Zhang, Y. Nishi, and H. Dai, J. Am. Chem. Soc. 128(11), 3518 (2006).

${ }^{21}$ J. Wang, M. Musameh, and Y. Lin, J. Am. Chem. Soc. 125(9), 2408 (2003).

${ }^{22}$ See supplementary material at http://dx.doi.org/10.1063/1.4802804 for FMWCNT synthesis and coating, plasma treatment, sintering methods, pool boiling experiments, visualization studies, and movies.

${ }^{23}$ A. Felten, C. Bittencourt, J. J. Pireaux, G. Van Lier, and J. C. Charlier, J. Appl. Phys. 98(7), 074308 (2005).

${ }^{24}$ K. Balasubramanian and M. Burghard, Small 1(2), 180 (2005).

${ }^{25}$ K. K. S. Lau, J. Bico, K. B. K. Teo, M. Chhowalla, G. A. J. Amaratunga, W. I. Milne, G. H. McKinley, and K. K. Gleason, Nano Lett. 3(12), 1701 (2003).

${ }^{26}$ A. B. D. Cassie and S. Baxter, Trans. Faraday Soc. 40, 546 (1944).

${ }^{27}$ R. N. Wenzel, Ind. Eng. Chem. 28(8), 988 (1936).

${ }^{28}$ A. Lafuma and D. Quere, Nature Mater. 2(7), 457 (2003).

${ }^{29}$ S. Boduroglu, M. Cetinkaya, W. J. Dressick, A. Singh, and M. C. Demirel, Langmuir 23(23), 11391 (2007).

${ }^{30}$ S. Lee, J.-W. Peng, and C.-H. Liu, Carbon 47(15), 3488 (2009).

${ }^{31}$ E. T. Mickelson, C. B. Huffman, A. G. Rinzler, R. E. Smalley, R. H. Hauge, and J. L. Margrave, Chem. Phys. Lett. 296(1-2), 188 (1998).

${ }^{32}$ V. N. Khabashesku, W. E. Billups, and J. L. Margrave, Acc. Chem. Res. 35(12), 1087 (2002) 